\title{
Anaesthetic considerations of adults with Morquio's syndrome - a case report
}

\author{
Anne Marie McLaughlin*, Muhammad Farooq, Maria B Donnelly, Kieran Foley
}

\begin{abstract}
Background: The anaesthetic management of patients with Morquio syndrome is complicated by a number of factors including odontoid hypoplasia, atlantoaxial instability, thoracic kyphosis, and deposition of mucopolysaccharides in the soft tissue of the oropharnyx.

Case presentation: Herein we describe the anaesthetic considerations and management of a 26 year old adult with Morquio syndrome, who presented for an elective hip replacement.

Conclusion: This report details an awake fiberoptic intubation in an adult with Morquio syndrome. We recommend that this approach be considered in patients with Morquio syndrome undergoing general anaesthesia.
\end{abstract}

\section{Background}

Morquio's syndrome also known as Mucopolysaccharidosis type IV is an autosomal recessive disorder caused by deficiency of n-acetylgalactosamine-6-sulphate. Morquio in Uruguay and Brailsford in England simultaneously described this syndrome in 1929[1]. The incidence is unknown but is estimated to be between 1 in 75000 population in Northern Ireland to 1 in 200000 population in British Columbia [2,3]. Morquio's syndrome is characterised by a defect in the degradation of keratin sulphate resulting in the accumulation of mucopolysaccharides. At birth, a patient with Morquio's syndrome may appear healthy, however as the child grows into adulthood, various manifestations of this syndrome begin to emerge, including coarse facial features, prognathism, a broad mouth, a short nose with anteverted nares and a flat bridge, widely spaced teeth and macrocephaly. Other features include aortic valve incompetence hepatomegaly, inguinal hernias, mixed hearing loss and ocular complications including clouding of the corneas, pigmented degenerative retinal lesions or glaucoma. Pulmonary complications include a restrictive defect due to kyphoscoliosis resulting in decreased lung volumes and ventilation-perfusion mismatching and central or obstructive sleep apnoea, which can result in pulmonary hypertension and cor pulmonale. Characteristic vertebral

\footnotetext{
* Correspondence: annemmclaughlin@gmail.com

Department of Anaesthesia and Critical Care, Adelaide and Meath National Children Hospital Dublin, Dublin, Ireland
}

abnormalities include anterior hypoplasia of T12, L1 or L2, which may give rise to lumbar kyphosis. Hypoplasia of the dens is a common and severe manifestation that may lead to atlantoaxial instability, compression of the cervical spinal cord, and complications during endotracheal intubation. The limb-bone abnormalities may include short diaphyses, curving of the metaphyses and poor development of the epiphyses. Pelvic abnormalities include widening of the acetabula, hypoplasia of the femoral heads, with valgus deformity of the femoral necks[4].

\section{Case presentation}

A 26 year old man with a background of Morquio syndrome, was admitted for an elective left total hip replacement. Osteoarthritis of the hips secondary to avascular necrosis of the head of femur bilaterally had been diagnosed. There was no past medical history of note; however review of systems revealed snoring and daytime somnolence, suggestive of obstructive sleep apnoea. Clinical inspection demonstrated a man of short stature, his weight was $63 \mathrm{Kg}$ and height $150 \mathrm{~cm}$, with a large head and short neck, the head appeared to be sitting directly on his thorax. On inspection the thorax had an increased anterior-posterior diameter and kyphosis. Clinical examination including respiratory, neurological and cardiovascular systems were normal. Pulmonary function testing and baseline laboratory tests were normal. 
Preoperative airway examination demonstrated bulky soft tissue in the pharynx, grade 2 macroglossia, an enlarged uvula and tonsils, an exuberant gag reflex and a Mallampatti grade II airway. Preanaesthetic neutral and extension cervical $x$-rays were performed and demonstrated a hypoplastic odontoid process, and widening of the atlanto axial joint upon flexion, the joint measured $3 \mathrm{~mm}$ in diameter, the upper limit of normal (figure 1). Magnetic Resonance Imaging (MRI) of the cervical spine revealed an intermedullary syrinx extending from the second cervical vertebra spine down to the thoracic spine (figure 2), this findings ruled out regional spinal anaesthesia. Based on these findings and after discussion with the patient, an awake fibreoptic intubation for the procedure was planned.

\section{Anesthetic Management}

Topicalisation of the airway was achieved with a combination of nebulised Xylocaine $4 \%$ followed by the gargling of topical Xylocaine 4\%, which was repeated four times, to ensure absorption by the oropharynx which in this case, was thickened by the deposition of mucopolysaccharide[5]. Finally $2 \mathrm{mls}$ of lidocaine $1 \%$ was administered percutaneously into the trachea. The patient was sedated with midazolam 6 milligrams $(\mathrm{mg})$ in 1-2 $\mathrm{mg}$ increments and 50 micrograms of fentanyl. The fibreoptic scope was inserted orally into the trachea via a Berman pharyngeal airway, the trachea was intubated with an 7.5 (millimeters internal diameter) endotracheal tube (Mallinckrodt, Athlone Ireland). The head was held in the neutral position during laryngoscopy. Once the endotracheal tube (ETT) was confirmed to be in the correct position by auscultation of breath sounds and by direct visualization of the ETT sitting in the trachea as seen through the fibrebronchocope and Et $\mathrm{CO} 2$ monitoring. Anaesthesia was initiated with intravenous (IV) propofol $150 \mathrm{mgs}$ and neuromuscular blockade was obtained using atracurium 50 mgs. An arterial line was inserted into the right radial artery for continuous invasive blood pressure monitoring and blood gas analysis as a means of monitoring the adequacy of ventilation or the development of pulmonary compromise. The patient

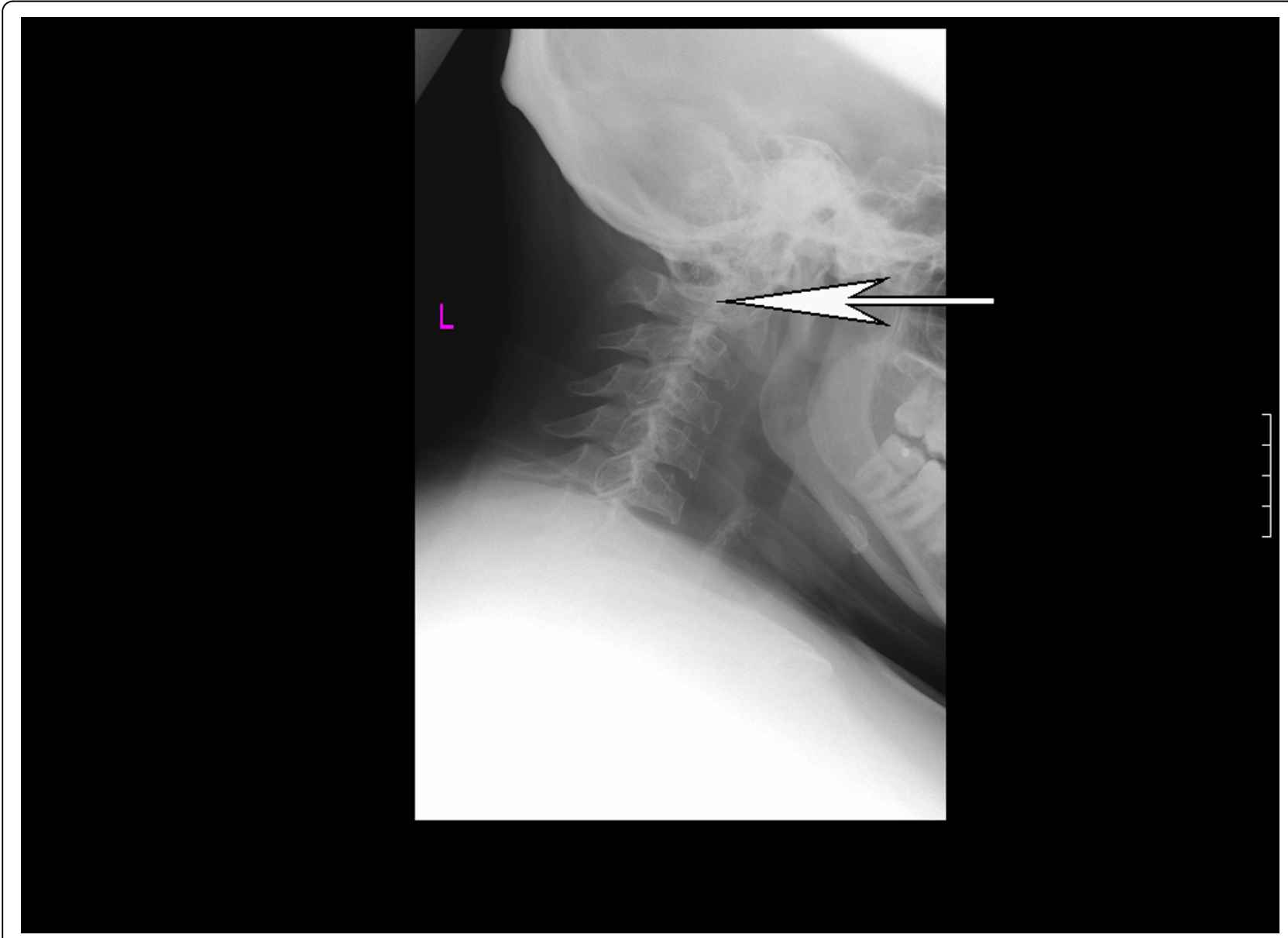

Figure 1 Lateral cervical spine x-ray demonstrating loss of normal cervical lordosis, anterior beaking of the cervical bodies and hypoplasia of odontoid peg. The atlanto axial space on flexion is $3 \mathrm{~mm}$, the upper limit of normal. 


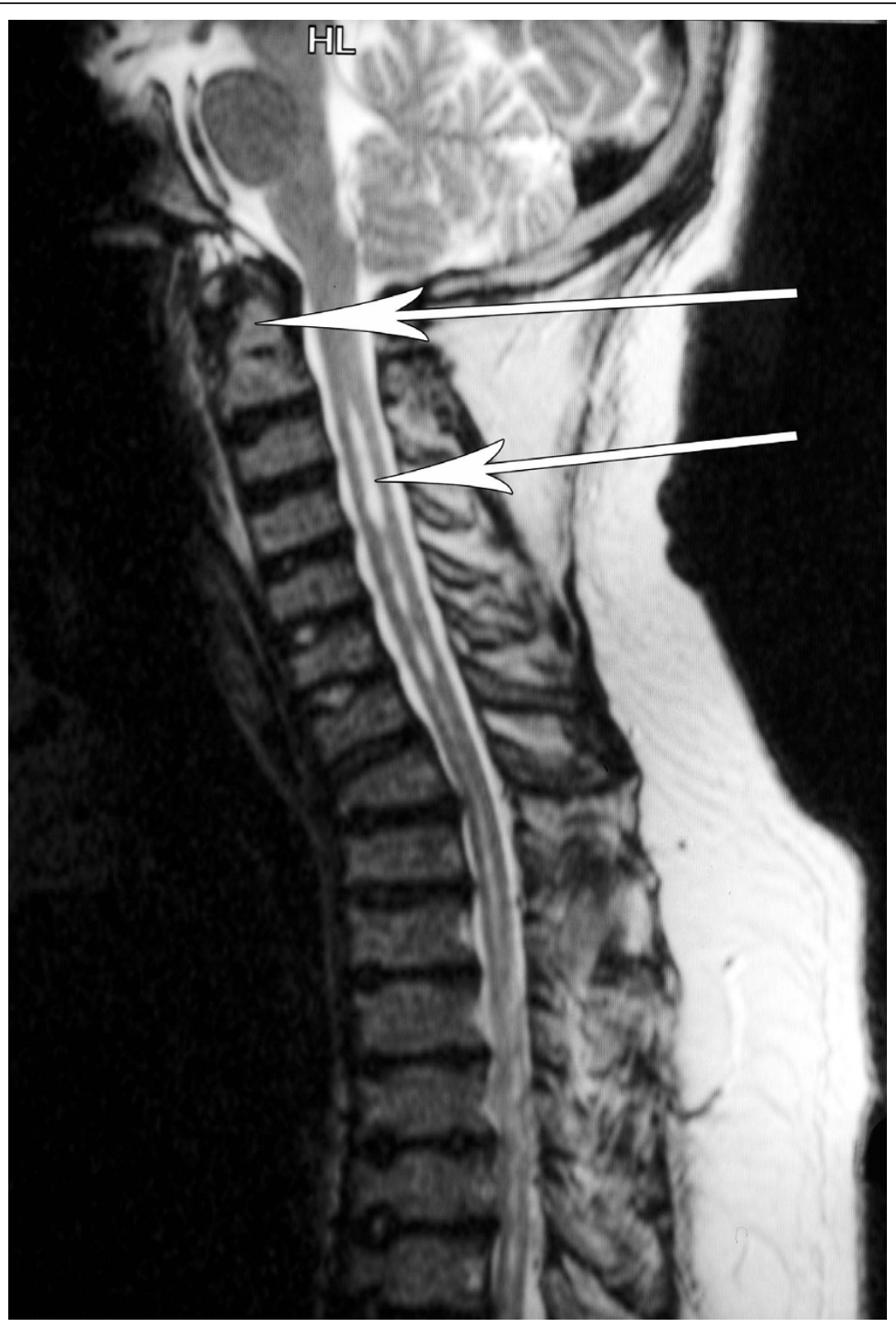

Figure 2 MRI cervical spine saggital section, with saturation band, anterior beaking of the cervical vertebrae and syrinx between C3 and $C 7$ is noted. Arrows indicate odontoid peg and syrinx.

was positioned on his left lateral side with lateral supports at the pelvis padded with absorbent cotton with gauze. Anaesthesia was subsequently maintained with a combination of an Oxygen/Nitrous Oxide/Sevoflurane mixture and IV Atracurium and Morphine sulphate 10 mg. One liter of Ringer's Lactate solution was infused IV during the case. The case proceeded uneventfully and at the end of the procedure the muscle relaxant was antagonized with IV Neostigmine $2.5 \mathrm{mg}$ along with 0.5 mg IV Glycopyrrolate. The patient resumed normal breathing and, the trachea was extubated awake and in the lateral position without complication. He was then transferred to the post anaesthetic care unit (PACU), where he recovered uneventfully and was monitored overnight. Recovery was uneventful. He is now planning to have the second hip replaced.

\section{Discussion}

Much controversy exists as to whether total hip replacement is best performed under neuraxial block or general anaesthesia (GA)[6]. However in Morquio syndrome the situation is more complex. Anaesthetic implications of 
Morquio syndrome relate to end-organ dysfunction and anatomical distortions related to the intracellular accumulation of keratin sulfate [7-9]. Difficulty in intubating the trachea is a result of a number of features in particular atlanto-axial instability and hypoplasia of the odontoid process. Additionally, bulky pharyngeal soft tissue due to the deposition of mucopolysaccharides in the soft tissues of the orophayrnx, floor of the mouth, epiglottis, aryepiglottic folds and macroglossia may mandate the use of a smaller endotrachael tube, furthermore the presence of prominent maxillae, limited mouth opening due to involvement of the temporomandibular joints and a short neck makes safe direct laryngoscopy difficult to perform. All of these factors may lead to a "cannot intubate/cannot ventilate" scenario. Furthermore, cervical spine instability in these patients is often not confirmed or excluded by adequate radiographic examination[10] and functional clinical testing and cervical spine stability may not be preserved in the deeply anesthetized patient with neuromuscular blockade.

The complexity of anaesthesia associated with Morquio syndrome has been previously published, particularly in paediatric literature. In a series reporting on occiptio-cervical fusion in 17 patients with Morquio syndrome (age 3-22) intubation under GA is described [11]. Video assisted intubation following gas induction is described in a case series of three pediatric patients undergoing GA for otorhinolaryngology surgery[12]. Furthermore, a case of spinal anaesthesia and a GA with inhalation induction in two children undergoing orthopaedic procedures, and an inhalation induction for a child undergoing stabilisation of cervical spine are described $[13,14]$. A specifically designed plaster bed which was used to fix the neck during intubation and surgery has been reported[15]. To avoid cervical cord damage in patients with cervical instability, Walker et al described manual in-line stabilisation during intubation [16]. Furthermore, 2 cardiac valve surgery cases under GA is described[17,18]. Nott describes an awake intubation in a patient with unstable neck after spraying the pharynx with topical lignocaine $4 \%$ and applying fentanyl and ketamine intravenously[19]. Awake fibreoptic intubations have been previously described in pediatric $[20,21]$ and adult [22] cases of Morquio syndrome. However, the deposition of soft tissue in the neck and oropharynx in Morquio syndrome may present difficulties for conventional fibreoptic intubation, mandating consideration of lighted stylets or fibreoptic stylets[23]. Successful use of a supraglottic airway device as a conduit for fibreoptic -guided tracheal intubation has been described in Hunters syndrome[24]. A preoperative awake fiberoptic examination of the airway by ENT services is advisable.

\section{Conclusion}

There is limited data on anaesthesia in adults with Morquio syndrome, general anaesthesia has been reported in paediatric and to a lesser extent adult patients. Paramount in the anaesthetic care of such patients is a thorough preoperative evaluation of airway in addition to cardiac, respiratory, neurological function.

\section{Acknowledgements}

Consent statement

Written informed consent was obtained from the patient for publication of this case report and accompanying images. A copy of the written consent is available for review by the Editor-in-Chief of this journal.

We appreciate the patient's consent to publish this report.

\section{Authors' contributions}

AMMCL prepared the manuscript and figures; MF, MD and KF each cared for the patient. All authors have read and approved the final manuscript.

\section{Competing interests}

The authors declare that they have no competing interests.

Received: 1 May 2009

Accepted: 26 February 2010 Published: 26 February 2010

\section{References}

1. Morquio L: Sur une forme de dystrophie osseuse familiale. Arch Med Enfants 1929, 32:129-140.

2. Lowry RB, Renwick DHG: Relevant frequency of the Hurler and Hunter syndromes. N Engl J Med 1971, 284:221-222.

3. Nelson J: Incidence of the mucopolysaccharidoses in Northern Ireland. Hum Genet 1997, 101(3):355-8.

4. Jones $\mathrm{KL}$ : Morquio syndrome. Smith's recognizable patterns of human malformation Elsevier Saunders, 6 2006, 538-539.

5. Walker PP, Rose E, Williams JG: Upper airways abnormalities and tracheal problems in Morquio's disease. T horax 2003, 58:458-459.

6. Mauermann WJ, Shilling AM, Zuo Z: A comparison of neuraxial block versus general anesthesia for elective total hip replacement: a metaanalysis. Anesth Analg 2006, 103:1018-25.

7. Shinhar SY, Zablocki H, Madgy DN: Airway management in mucopolysaccharide storage disorders. Arch Otolaryngol Head Neck Surg 2004, 130:233-7.

8. Baines D, Keneally J: Anaesthetic implications of the mucopolysaccharidosis: a fifteen-year experience in a children's hospital. Anaesth Intens Care 1983, 11:198-202.

9. Birkinshaw KJ: Anaesthesia in a patient with an unstable neck. Morquio's syndrome. Anaesthesia 1975, 30(1):46-49.

10. Kulkarni MV, Williams JC, Yeakley JW, et al: Magnetic resonance imaging in the diagnosis of the cranio- cervical manifestations of the mucopolysaccaridoses. Magn Reson Imaging 1987, 5:317-323.

11. Ransford AO, Crockard HA, Modaghegh S: Occipito-atlanto-axial fusion in Morquio-Brailsford Syndrome. J Bone Joint Surg Br 1996, 78:307-313.

12. Dullenkopf A, Holzmann D, Feure R, Gerber A, Weiss M: Tracheal intubation in children with Morquio syndrome using the angulated video-intubation laryngoscope. Can J Anesth 2002, 49:198-202.

13. Tobias JD: Anesthetic care for the child with morquio syndrome; General versus regional anesthesia. J Clin Anesth 1999, 11:242-6.

14. Morgan KA, Rehman MA, Schwartz RE: Morquio syndrome and its anesthetic considerations. Paediatr Anaesth 2002, 12:641-644.

15. Birkinshaw KJ: Anaesthesia in a patient with an unstable neck. Morquio's syndrome. Anaesthesia 1975, 30:46-49.

16. Walker RW, Darowski M, Morris P, Wraith JE: Anaesthesia and mucopolysaccharidoses. A review of airway problems in children. Anaesthesia 1994, 49:1078-1084.

17. Nicolini F, Corradi D, Bosio S, Gherli T: Aortic valve replacement in a patient with morquio syndrome. Heart Surg Forum 2008, 11:E96-8. 
18. Barry MO, Beardslee MA, Braverman AC: Morquio's syndrome: severe aortic regurgitation and late pulmonary autograft failure. $J$ Heart Valve Dis 2006, 15(6):839-42.

19. Nott MR, al Hajaj WH: Anaesthesia for urinary diversion with ileal conduit in a patient with Morquio-Brailsford syndrome. Anaesth Intensive Care 1993, 21:879-884.

20. Tzanova I, Schwarz M, Jantzen JP: Securing the airway in children with the Morquio-Brailsford syndrome. Anaesthesist 1993, 42:477-481.

21. Bartz HJ, Wiesner L, Wappler F: Anaesthetic management of patients with mucopolysaccharidosis IV presenting for major orthopaedic surgery. Acta Anaesthesiol Scand 1999, 43:679-683.

22. Pagel PS, Almassi GH: Periopertative implications of Morquio syndrome in a 31-year old women undergoing aortic valve replacement. $J$ Cardiothorac Vasc Anesth 2009, 6:855-57.

23. Aucoin S, Vlatten A, Hackmann T: Difficult airway management with the Bonfils fiberscope in a child with Hurler syndrome. Paediatr Anaesth 2009, 19:421-2.

24. Michalek P, Hodgkinson $P$, Donaldson W: Fibreoptic intubation through an I-Gel supraglottic airway in two patients with predicated difficult airway and intellectual disability. Anaesthesia analgesia 2008, 5:1501-1504.

\section{Pre-publication history}

The pre-publication history for this paper can be accessed here:http://www. biomedcentral.com/1471-2253/10/2/prepub

doi:10.1186/1471-2253-10-2

Cite this article as: McLaughlin et al: Anaesthetic considerations of adults with Morquio's syndrome - a case report. BMC Anesthesiology $201010: 2$.

\section{Submit your next manuscript to BioMed Central and take full advantage of:}

- Convenient online submission

- Thorough peer review

- No space constraints or color figure charges

- Immediate publication on acceptance

- Inclusion in PubMed, CAS, Scopus and Google Scholar

- Research which is freely available for redistribution

Submit your manuscript at www.biomedcentral.com/submit 